ARTICLE

\title{
Tuning the reactivity of alkoxyl radicals from 1,5- hydrogen atom transfer to 1,2-silyl transfer
}

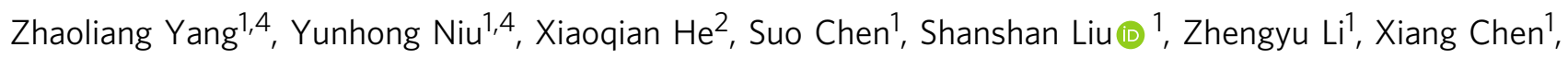
Yunxiao Zhang ${ }^{1}$, Yu Lan (iD ${ }^{2,3 凶} \&$ Xiao Shen (1D ${ }^{1 凶}$

Controlling the reactivity of reactive intermediates is essential to achieve selective transformations. Due to the facile 1,5-hydrogen atom transfer (HAT), alkoxyl radicals have been proven to be important synthetic intermediates for the $\delta$-functionalization of alcohols. Herein, we disclose a strategy to inhibit 1,5-HAT by introducing a silyl group into the $\alpha$-position of alkoxyl radicals. The efficient radical 1,2-silyl transfer (SiT) allows us to make various $\alpha$ functionalized products from alcohol substrates. Compared with the direct generation of $\alpha$ carbon radicals from oxidation of $\alpha-\mathrm{C}-\mathrm{H}$ bond of alcohols, the 1,2-SiT strategy distinguishes itself by the generation of alkoxyl radicals, the tolerance of many functional groups, such as intramolecular hydroxyl groups and $\mathrm{C}-\mathrm{H}$ bonds next to oxygen atoms, and the use of silyl alcohols as limiting reagents.

\footnotetext{
${ }^{1}$ The Institute for Advanced Studies, Engineering Research Center of Organosilicon Compounds and Materials, Ministry of Education, Wuhan University, Wuhan, People's Republic of China. ${ }^{2}$ School of Chemistry and Chemical Engineering, Chongqing Key Laboratory of Theoretical and Computational Chemistry, Chongqing University, Chongqing, People's Republic of China. ${ }^{3}$ College of Chemistry and Molecular Engineering, Zhengzhou University,

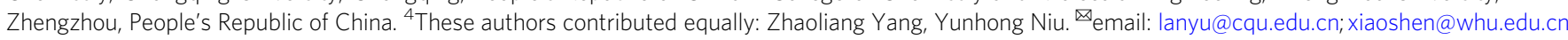


R adicals, anions, cations, carbenes, and others are key reactive intermediates in synthesis ${ }^{1}$. These intermediates usually show different reactivity, facilitating the development of complementary methodologies for the synthesis of molecules that are important in material and/or life-related field ${ }^{2-4}$. Among various radicals, alkoxyl radicals have gained increasing attention (Fig. 1a) ${ }^{5-9}$. Although the previous studies to generate alkoxyl radicals usually need pre-activated alcohols or corresponding precursors ${ }^{10-21}$, recent work on the direct activation of alcohols with photocatalysis and/or transition-metal catalysis largely broaden their synthetic utility ${ }^{22-29}$. When $\delta-\mathrm{C}-\mathrm{H}$ bonds are present, the intramolecular 1,5-hydrogen atom transfer (HAT) from the $\delta$-position via a low-energy six-membered ring transition state is usually favored over the transfer of hydrogen atoms at other positions, thus alkoxyl radical-mediated $\delta-\mathrm{C}-\mathrm{H}$ functionalization is widely studied (Fig. 1b) ${ }^{6}$. For example, the synthesis of $\delta$-alkoxylimino alcohols and intermolecular $\delta$ heteroarylation of alcohols through 1,5-HAT of alkoxyl radicals have been achieved (Fig. 1b) ${ }^{27-29}$. However, alkoxyl radicalmediated $a$-functionalization of alcohols have not been reported $^{30,31}$. It is also known that excess amount of alcohols are usually required in oxidative $\mathrm{C}-\mathrm{H}$ functionalization reactions, and it is challenging to control the selectivity when multiple oxidizable $\mathrm{C}-\mathrm{H}$ bonds are present in the substrate ${ }^{30,31}$. Silicon possesses empty $d$ orbitals and $\mathrm{C}-\mathrm{Si}$ bond is longer than $\mathrm{C}-\mathrm{H}$ bond. We envisioned that 1,2-silyl transfer ( $\mathrm{SiT}$ ) of alkoxyl radical via three-membered ring transition state (also known as radical Brook rearrangement, RBR) might be easier than the corresponding 1,2-HAT and might be favored over 1,5-HAT process (Fig. 1c).

RBR was initially proposed to explain the cyclopropanation product of the photoreaction between acylsilanes and electronpoor olefins in 1981 $32-35$. However, the synthetic application of RBR was nearly ignored in the following decades ${ }^{35-38}$. Until 2017 , Smith and group found that benzylic radicals can be generated from the oxidation of hypervalent silicate intermediate by a photo-excited Ir complex ${ }^{37}$. In 2020, our group revealed that the Mn-catalyzed RBR is superior to anion Brook rearrangement in the direct trifluoroethanol transfer reactions ${ }^{38}$. Herein, we show that radical 1,2-SiT is favored over 1,5-HAT under Ag-catalysis conditions, and selective $\mathrm{a}-\mathrm{C}-\mathrm{C}$ bond formation reactions are achieved without any $\delta$-functionalization product, in which the use of alcohols as limiting reagents in the reaction of oxime ethers and the tolerance of various $\mathrm{C}-\mathrm{H}$ bonds and benzyl alcohols demonstrate the synthetic potential of our methodology (Fig. 1c) $)^{30,31}$.

\section{Results}

Radical 1,2-SiT in the synthesis of a-hydroxyl oxime ethers. Oximes and oxime ethers are important synthetic building blocks, and they have also been found to be core structural motifs of multiple bioactive molecules ${ }^{28,39-41}$. In 2018, Jiao and co-workers reported the synthesis of $\delta$-alkoxylimino alcohols through 1,5 HAT of alkoxyl radicals, but no a-alkoxylimino alcohols were isolated ${ }^{28}$. Previous methods to prepare $\alpha$-hydroxyl oxime ethers mainly rely on the reduction of alkoxyliminyl substituted ketones, which themselves need multistep synthesis ${ }^{41}$. To the best of our knowledge, there is no report on radical-mediated synthesis of $\alpha$ alkoxylimino alcohols. Therefore, we choose to investigate the reaction between $\alpha$-silyl alcohol 1a and sulfonyl oxime ether 2 to check whether $\alpha$-functionalization product or $\delta$-functionalization product can be obtained.

Optimization of the reaction conditions for the synthesis of $\alpha$ hydroxyl oxime ethers. Previously, we found the $\mathrm{Mn}(\mathrm{II}) / \mathrm{Mn}$ (III)-catalyzed metal alkoxide (M-OR) homo-cleavage strategy was an efficient way to generate alkoxyl radicals for the direct transfer of trifluoroethanol and difluoroethanol units ${ }^{38}$. Therefore, we focused on the investigation of various transition-metal salts for M-OR homo-cleavage. After extensive investigations, we found that $\mathrm{AgNO}_{3}$ was a better pre-catalyst than $\mathrm{CuCl}_{2}, \mathrm{FeCl}_{3}$, $\mathrm{NiBr}_{2}, \mathrm{Mn}(\mathrm{OAc})_{3}$, and $\mathrm{AgI}$ (Fig. 2, entries 1-6). When the reaction was carried out in $\mathrm{MeCN} / \mathrm{H}_{2} \mathrm{O}(\mathrm{v} / \mathrm{v}=1: 1)$ at $80^{\circ} \mathrm{C}$ for $12 \mathrm{~h}$ with $\mathrm{K}_{2} \mathrm{~S}_{2} \mathrm{O}_{8}$ as an oxidant, a yield of $47 \%$ was afforded for compound 3a, without any detection of $\delta$-functionalization product (entry 6). When the solvent was changed to acetone/ $\mathrm{H}_{2} \mathrm{O}(\mathrm{v} /$ $\mathrm{v}=1: 1$ ), the yield of $\mathbf{a}$-functionalization product $3 \mathbf{a}$ increased to $51 \%$ (entry 7 ). Increasing the concentration of the reaction resulted in an improved yield of compound 3a (71\%, entry 8). Other oxidants such as $\mathrm{Na}_{2} \mathrm{~S}_{2} \mathrm{O}_{8},\left(\mathrm{NH}_{4}\right)_{2} \mathrm{~S}_{2} \mathrm{O}_{8}$, Dess-Martin periodinane, and tert-butyl peroxybenzoate afforded lower efficiency of the reaction (entries 9-12). Lowering the reaction temperature also resulted in a decreased yield of compound $\mathbf{3 a}$ (entries 13 and 14). The control experiment showed that, without $\mathrm{AgNO}_{3}$, only $20 \%$ yield of compound 3a was observed by proton a Alkoxyl radicals:important synthetic intermediates

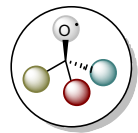

b Previous work: selective 1,5-HAT of alkoxyl radicals
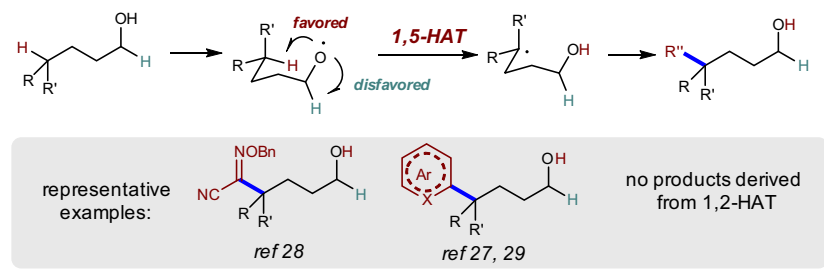

C This work: 1,2-SiT of alkoxyl radicals which contain d-C-H bonds

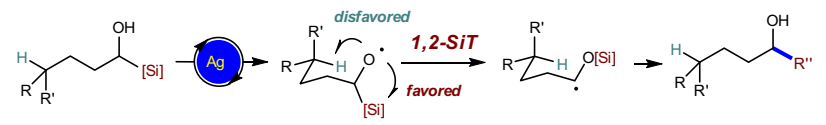

[Si]: silyl group

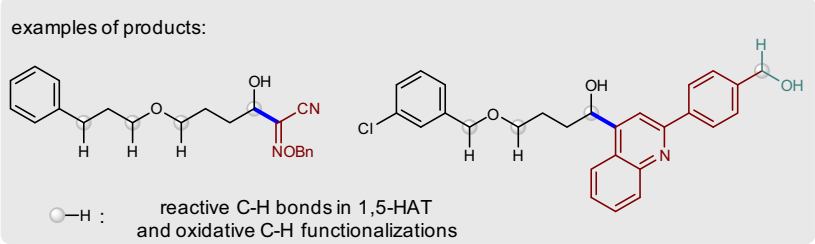

Fig. 1 Tuning the reactivity of alkoxyl radicals from 1,5-HAT to 1,2-SiT by the incorporation of a silyl group. a Alkoxyl radicals are important synthetic intermediates. b Intramolecular 1,5-hydrogen atom transfer (HAT) via a six-membered ring transition state is usually favored over the transfer of hydrogen atoms at other positions, thus alkoxyl radicals mediated $\delta-\mathrm{C}-\mathrm{H}$ functionalization is widely studied. c We disclose here that 1,2-silyl transfer (SiT) is favored over 1,5-HAT under Ag-catalyzed conditions, allowing the efficient synthesis of $\alpha$-hydroxyl oxime ethers and $\alpha$-heteroaryl alcohols (this work). The alkoxyl radical-mediated reactions can tolerate many reactive $\mathrm{C}-\mathrm{H}$ bonds, which are reactive in $1,5-\mathrm{HAT}$ and oxidative $\mathrm{C}-\mathrm{H}$ functionalizations. Another $\mathrm{OH}$ group in the substrates can also be tolerated. 


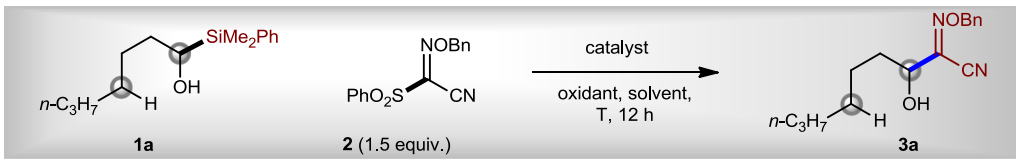

\begin{tabular}{|c|c|c|c|c|c|c|c|}
\hline Entry & Catalyst & Oxidant & Solvent $(V / V=1: 1)$ & $\mathrm{T} /{ }^{\circ} \mathrm{C}$ & Conv. of $1 \mathbf{a}(\%)$ & Conv. of $\mathbf{2}(\%)$ & Yield of $\mathbf{3 a}(\%)$ \\
\hline 1 & $\mathrm{CuCl}_{2}$ & $\mathrm{~K}_{2} \mathrm{~S}_{2} \mathrm{O}_{8}$ & $\mathrm{MeCN}: \mathrm{H}_{2} \mathrm{O}$ & 80 & 94 & 94 & 15 \\
\hline 2 & $\mathrm{FeCl}_{3}$ & $\mathrm{~K}_{2} \mathrm{~S}_{2} \mathrm{O}_{8}$ & $\mathrm{MeCN}: \mathrm{H}_{2} \mathrm{O}$ & 80 & 95 & 44 & 20 \\
\hline 3 & $\mathrm{NiBr}_{2}$ & $\mathrm{~K}_{2} \mathrm{~S}_{2} \mathrm{O}_{8}$ & $\mathrm{MeCN}: \mathrm{H}_{2} \mathrm{O}$ & 80 & $>99$ & 50 & 29 \\
\hline 4 & $\mathrm{Mn}(\mathrm{OAc})_{3}$ & $\mathrm{~K}_{2} \mathrm{~S}_{2} \mathrm{O}_{8}$ & $\mathrm{MeCN}: \mathrm{H}_{2} \mathrm{O}$ & 80 & $>99$ & 93 & 33 \\
\hline 5 & $\mathrm{Agl}$ & $\mathrm{K}_{2} \mathrm{~S}_{2} \mathrm{O}_{8}$ & $\mathrm{MeCN}: \mathrm{H}_{2} \mathrm{O}$ & 80 & 96 & 90 & 14 \\
\hline 6 & $\mathrm{AgNO}_{3}$ & $\mathrm{~K}_{2} \mathrm{~S}_{2} \mathrm{O}_{8}$ & $\mathrm{MeCN}: \mathrm{H}_{2} \mathrm{O}$ & 80 & $>99$ & 61 & 47 \\
\hline 7 & $\mathrm{AgNO}_{3}$ & $\mathrm{~K}_{2} \mathrm{~S}_{2} \mathrm{O}_{8}$ & Acetone $\mathrm{H}_{2} \mathrm{O}$ & 80 & $>99$ & 96 & 51 \\
\hline $8^{b}$ & $\mathrm{AgNO}_{3}$ & $\mathrm{~K}_{2} \mathrm{~S}_{2} \mathrm{O}_{8}$ & Acetone $\mathrm{H}_{2} \mathrm{O}$ & 80 & $>99$ & 86 & 71 \\
\hline $9^{b}$ & $\mathrm{AgNO}_{3}$ & $\mathrm{Na}_{2} \mathrm{~S}_{2} \mathrm{O}_{8}$ & Acetone $\mathrm{H}_{2} \mathrm{O}$ & 80 & $>99$ & 96 & 50 \\
\hline $10^{\mathrm{b}}$ & $\mathrm{AgNO}_{3}$ & $\left(\mathrm{NH}_{4}\right)_{2} \mathrm{~S}_{2} \mathrm{O}_{8}$ & Acetone $\mathrm{H}_{2} \mathrm{O}$ & 80 & $>99$ & 93 & 55 \\
\hline $11^{\mathrm{b}}$ & $\mathrm{AgNO}_{3}$ & DMP & Acetone: $\mathrm{H}_{2} \mathrm{O}$ & 80 & $>99$ & 26 & $<1$ \\
\hline $12^{\mathrm{b}}$ & $\mathrm{AgNO}_{3}$ & TBPB & Acetone: $\mathrm{H}_{2} \mathrm{O}$ & 80 & 28 & $<2$ & $<1$ \\
\hline $13^{\mathrm{b}}$ & $\mathrm{AgNO}_{3}$ & $\mathrm{~K}_{2} \mathrm{~S}_{2} \mathrm{O}_{8}$ & Acetone $\mathrm{H}_{2} \mathrm{O}$ & 50 & $>99$ & 94 & 55 \\
\hline $14^{\mathrm{b}}$ & $\mathrm{AgNO}_{3}$ & $\mathrm{~K}_{2} \mathrm{~S}_{2} \mathrm{O}_{8}$ & Acetone $: \mathrm{H}_{2} \mathrm{O}$ & 25 & 72 & 53 & 32 \\
\hline $15^{\mathrm{b}}$ & I & $\mathrm{K}_{2} \mathrm{~S}_{2} \mathrm{O}_{8}$ & Acetone $\mathrm{H}_{2} \mathrm{O}$ & 80 & 78 & 91 & 20 \\
\hline $16^{\mathrm{b}}$ & $\mathrm{AgNO}_{3}$ & I & Acetone $\mathrm{H}_{2} \mathrm{O}$ & 80 & 4 & 3 & $<1$ \\
\hline
\end{tabular}

Fig. 2 Reaction optimization. TThe mixture of $\mathbf{1 a}(0.2 \mathrm{mmol})$, catalyst $(0.04 \mathrm{mmol})$, oxidant $(0.4 \mathrm{mmol})$, and $\mathbf{2}(0.3 \mathrm{mmol})$ in the solvent $(2 \mathrm{~mL})$ was stirred at $T$ under $\mathrm{N}_{2}$ for $12 \mathrm{~h}$. Conversions of $\mathbf{1 a}$ and $\mathbf{2}$ and yield of $\mathbf{3 a}$ were determined by ${ }^{1} \mathrm{H}$ NMR using $\mathrm{BrCH}_{2} \mathrm{CH}_{2} \mathrm{Br}$ as an internal standard. bSolvent (1.5 $\mathrm{mL}$ ). DMP Dess-Martin periodinane, TBPB tert-butyl peroxybenzoate.

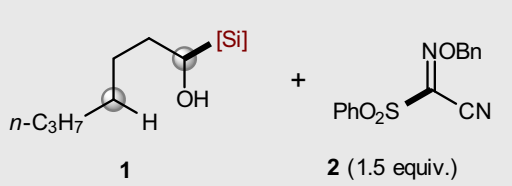

2 (1.5 equiv.)

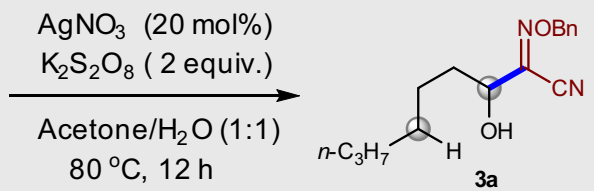

1) with $1 \mathrm{a}\left([\mathrm{Si}]=\mathrm{PhMe}_{2} \mathrm{Si}\right),>99$ conv. of $1 \mathrm{a}, 86 \%$ conv. of $2,71 \%$ yield of $3 \mathrm{a}$;

2) with $1 \mathrm{ab}\left([\mathrm{Si}]=\mathrm{Me}_{3} \mathrm{Si}\right)$, $>99$ conv. of $1 \mathrm{ab}, 91 \%$ conv. of $2, \mathbf{4 1 \%}$ yield of $3 \mathrm{a}$;

3 ) with $1 \mathrm{ac}\left([\mathrm{Si}]=t-\mathrm{BuMe}_{2} \mathrm{Si}\right),>99$ conv. of $1 \mathrm{ac}, 92 \%$ conv. of $2,13 \%$ yield of $3 \mathrm{a}$;

4) with $1 \mathrm{ad}\left([\mathrm{Si}]=\mathrm{Ph}_{2} \mathrm{MeSi}\right), 92 \%$ conv. of $1 \mathrm{ad}, 90 \%$ conv. of $\mathbf{2}, \mathbf{4 8} \%$ yield of $3 \mathrm{a}$;

5) with $1 \mathrm{ae}\left([\mathrm{Si}]=\mathrm{Ph}_{3} \mathrm{Si}\right), 81 \%$ conv. of $1 \mathrm{ae}, 72 \%$ conv. of $2,31 \%$ yield of $3 \mathrm{a}$.

Fig. 3 Influence of silyl groups on the efficiency of the reaction. Reaction conditions: the mixture of $\mathbf{1}(0.2 \mathrm{mmol}), \mathrm{AgNO}_{3}(0.04 \mathrm{mmol}), \mathrm{K}_{2} \mathrm{~S}_{2} \mathrm{O}_{8}(0.4$ mmol), $\mathbf{2}(0.3 \mathrm{mmol})$, and acetone $/ \mathrm{H}_{2} \mathrm{O}(0.75 \mathrm{~mL} / 0.75 \mathrm{~mL})$ was stirred at $80{ }^{\circ} \mathrm{C}$ under $\mathrm{N}_{2}$ for $12 \mathrm{~h}$. Conversion of $\mathbf{1}$ and $\mathbf{2}$ and yield of $\mathbf{3 a}$ were determined by ${ }^{1} \mathrm{H}$ NMR using $\mathrm{BrCH}_{2} \mathrm{CH}_{2} \mathrm{Br}$ as an internal standard.

nuclear magnetic resonance, although a large amount of decomposition of compounds 1a and 2 (entry 15) were found. However, no 3a was generated without $\mathrm{K}_{2} \mathrm{~S}_{2} \mathrm{O}_{8}$, and the conversions of compounds $\mathbf{1 a}$ and $\mathbf{2}$ were also low, indicating that $\mathrm{AgNO}_{3}$ alone cannot catalyze the reaction (entry 16).

Influence of silyl groups on the efficiency of the reaction. Encouraged by the favored $\alpha$-functionalization over $\delta$ functionalization in the reaction between compounds $\mathbf{1 a}$ and 2, we then investigated the influence of the silyl substituent on the efficiency of the desired $\alpha$-functionalization reaction. It was found that both electronic property and steric hindrance of the silyl group showed a significant effect on our reaction. The electronwithdrawing effect of the phenyl group on the silicon atom appears to play a positive role in this reaction (Fig. 3). However, the steric hindrance on the silicon atom shows a negative effect in this reaction (1a vs $1 \mathbf{a d}$ and $1 \mathbf{a e} ; \mathbf{1} \mathbf{a b}$ vs $\mathbf{1 a c}$ ). In all cases, aldehyde derived from compound $\mathbf{1}$ was formed as by-product. The substituents might not only affect the transfer ability of the silyl group but also affect the stability and reactivity of the radical intermediate III (see below). Moreover, the different substituents of the silyl groups also affect the C-Si bond length and bond dissociation energy, which might also be important factors in 1,2-SiT. Again, none of the reactions afforded $\delta$-functionalization product. 


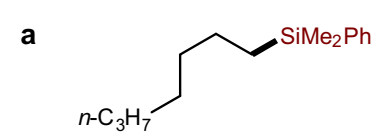

1a-1

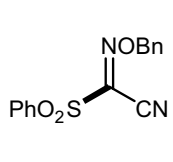

2

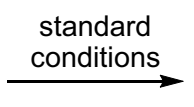

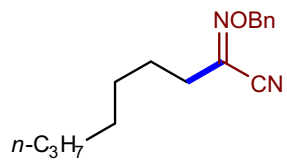

3a-1

$0 \%$ yield

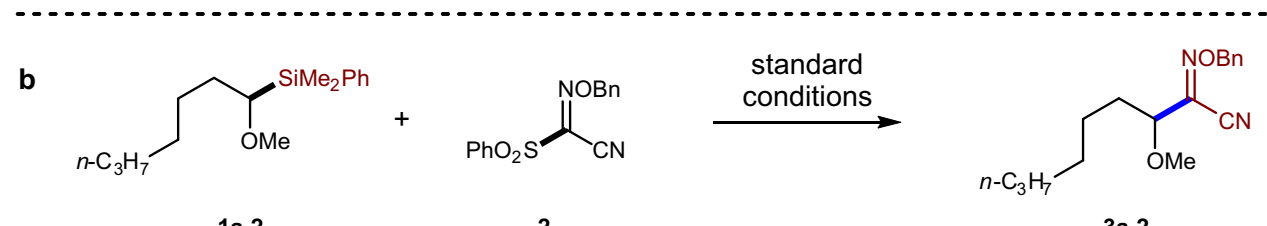

1a-2

2

3a-2

$5 \%$ yield
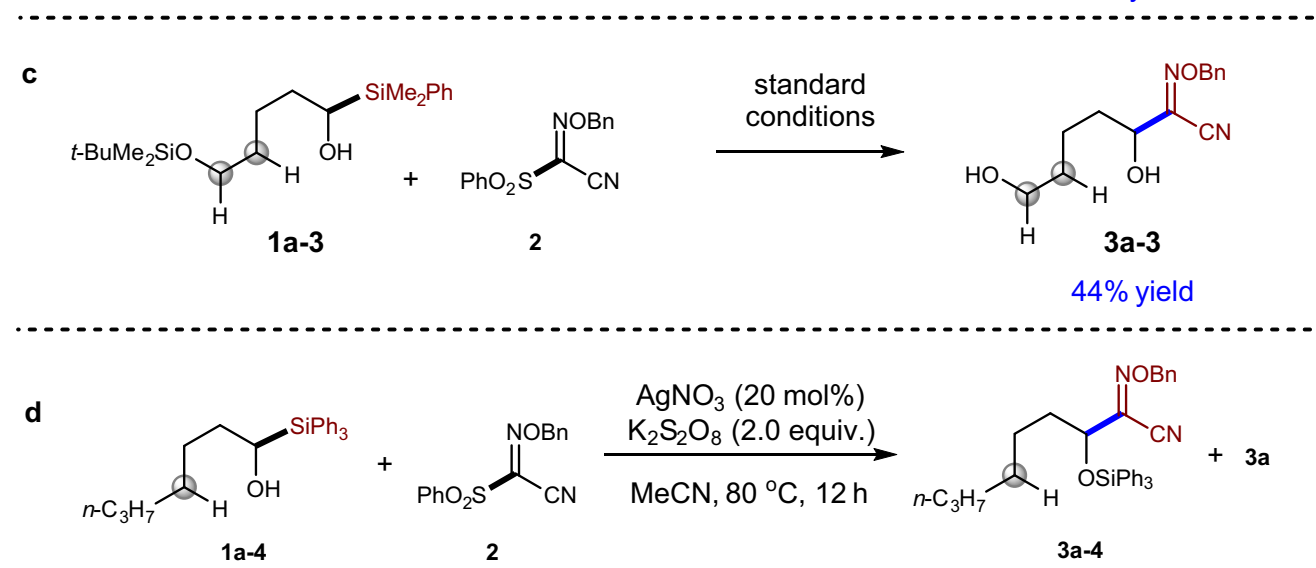

$10 \%$ yield of $3 a-4,2 \%$ yield of $3 a$

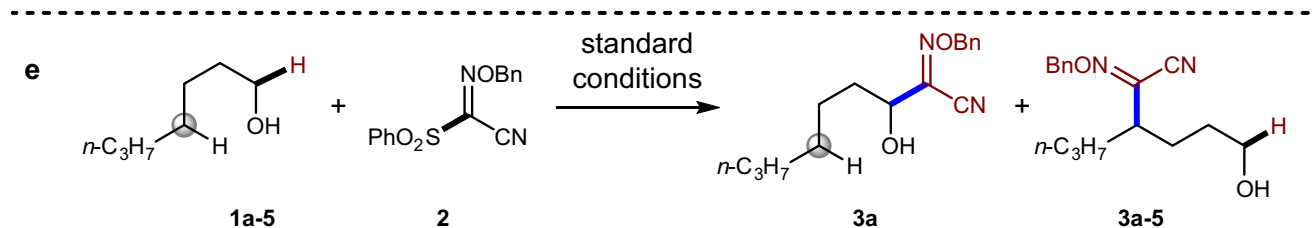

$0 \%$ yield of $3 a, 40 \%$ yield of $3 a-5$

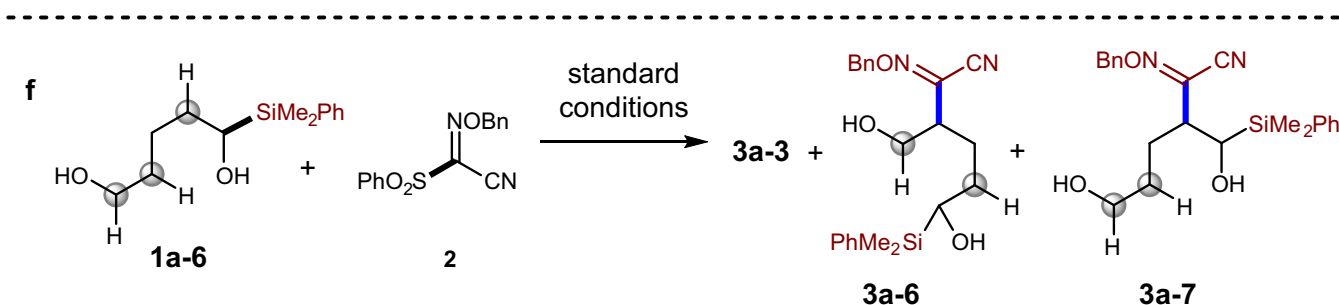

$38 \%$ yield of $3 a-3 ;<1 \%$ yield of $3 a-6,<1 \%$ yield of $3 a-7$

Fig. 4 Mechanistic studies. a Failure of the reaction with heptyldimethyl(phenyl)silane 1a-1 indictates the importance of $\mathrm{OH}$ group in the success of the reactions. $\mathbf{b}$ Failure of the reaction of protected $\alpha$-silyl alcohol $\mathbf{1 a - 2}$ indicates that direct oxidative cleavage of C-Si bond is less likely. $\mathbf{c}$ Reaction $\mathbf{1 a - 3}$ shows that silyl ether group could be hydrolyzed under the reaction conditions. d Reaction of $\alpha$-triphenylsilyl alcohol $\mathbf{1 a - 4}$ under conditions without $\mathrm{H}_{2} \mathrm{O}$ could afford non-desilylated product 3a-4. e The reaction of non-silylated alcohol 1a-5 indeed afforded 1,5-HAT product 3a-5 without the formation of afunctionalization product 3a. f Remote $\mathrm{OH}$ group in $\mathbf{1 a - 6}$ can be tolerated.

Mechanism study. After identification of a suitable silyl group to promote the efficient synthesis of $a$-alkoxylimino alcohol 3a, we set to investigate whether the reaction proceeded through radical 1,2 -SiT or not. Firstly, our study reveals that the $\mathrm{OH}$ group is important for the success of the reaction. The use of compound 1a-1 as starting material resulted in no anticipated product 3a-1 (Fig. 4a). Protected $a$-silyl alcohol 1a-2 only gave $5 \%$ yield of compound 3a-2 (Fig. 4b), indicating that the generation of carbon radical via direct oxidative cleavage of $\mathrm{C}-\mathrm{Si}$ bond is less likely to be the major pathway in the reaction with $\mathbf{1 a}^{42-45}$. This result was consistent to the similar oxidation potential of $\alpha$-silyl alcohol and the methyl-protected counterpart ${ }^{46}$. When silyl ether compound 1a-3 was applied in the reaction with compound 2, free diol 3a-3 was obtained in $44 \%$ yield (Fig. $4 \mathrm{c}$ ), suggesting that silyl ether can 
$\Delta G_{\text {M06-2X }}($ Acetonitrile $) /(\mathrm{kcal} / \mathrm{mol})$
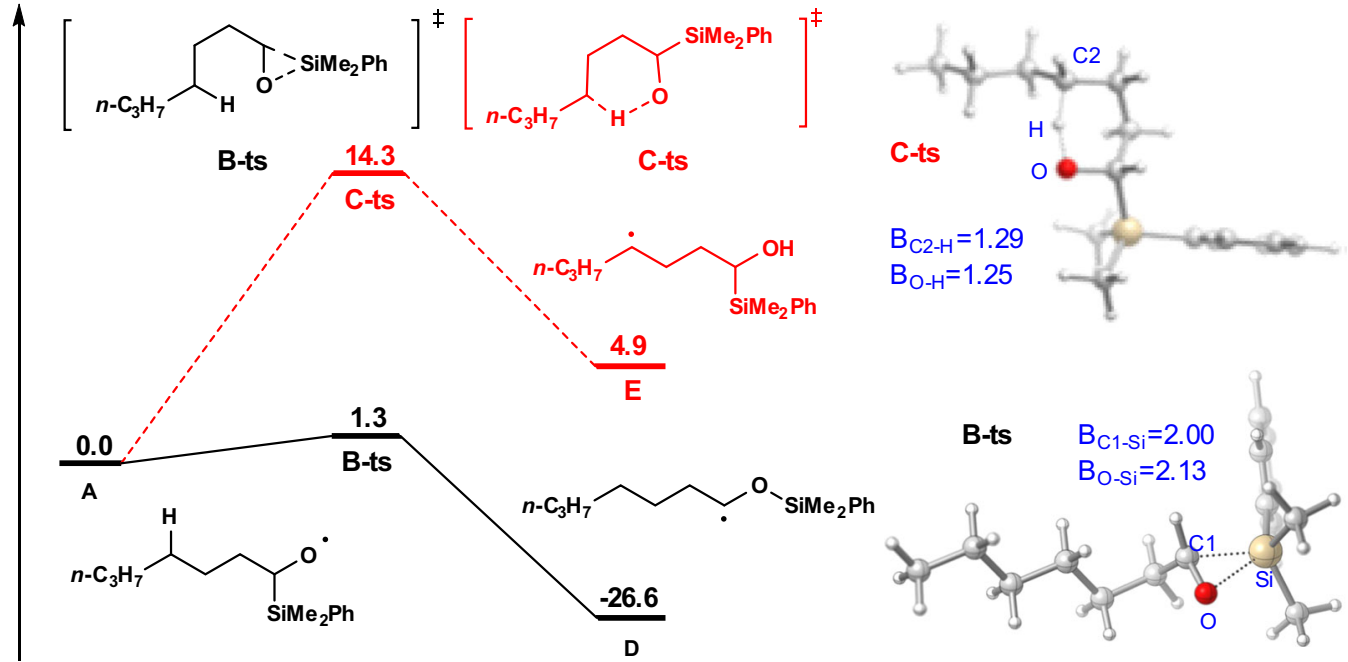

Fig. 5 Free-energy profile of the pathways for 1,2-SiT vs 1,5-HAT. The energies are in $\mathrm{kcal} / \mathrm{mol}$ and represent the relative free energies calculated with the DFT/M06-2X method in MeCN. The bond distances are in angstroms.

be hydrolyzed under aqueous reaction condition. Further study of the reaction of triphenylsilyl-substituted alcohol $\mathbf{1 a - 4}$ with compound 2 under no $\mathrm{H}_{2} \mathrm{O}$ condition showed that compound $\mathbf{3 a - 4}$ could be synthesized in $10 \%$ yield with $2 \%$ yield of desilylated compound 3a (Fig. 4d). The lower yield of $\mathbf{3 a - 4}$ and $\mathbf{3 a}$ might be explained by the low solubility under the non-aqueous conditions (Fig. 4d). Jiao and co-workers have shown that alcohols can participate in $\delta$-functionalization via radical 1,5 -HAT under Ag catalysis $^{28}$. The reaction of non-silylated alcohol 1a-5 indeed afforded 1,5-HAT product $\mathbf{3 a - 5}$ in $40 \%$ yield without the formation of a-functionalization product 3a (Fig. 4e). Interestingly, when a silyl alcohol 1a-6, which contains another $\mathrm{C}-\mathrm{OH}$ bond, was tested in the reaction with compound 2, the major product is C-Si bond functionalization product 3a-3 (38\% yield; Fig. 4f), further indicating radical 1,2 -SiT is favored over 1,5 -HAT. The tolerance of free alcohol is an advantage of our method, since diols are challenging substrates for the oxidative $\mathrm{C}-\mathrm{H}$ bond functionalization chemistry ${ }^{30,31}$.

Subsequently, we investigated the energy barrier of 1,2-SiT and 1,5-HAT of alkoxyl radical intermediate $\mathbf{A}$ using density functional theory (DFT) calculation employing the method M06-2X (for details, see the Supplementary information $3 \mathrm{i}-\mathrm{n})^{47-49}$. As shown in Fig. 5, alkoxyl radical $\mathbf{A}$ was set as the starting point for the free-energy profiles. 1,2-SiT via transition state $\mathbf{B}$-ts to generate radical intermediate $\mathbf{D}$ is quite easy with an energy barrier of only $1.3 \mathrm{kcal} / \mathrm{mol}$, and this process is exothermic $(26.6 \mathrm{kcal} / \mathrm{mol})$. However, $1,5-\mathrm{HAT}$ via transition state C-ts to generate radical intermediate $\mathbf{E}$ is an endothermic reaction (4.9 $\mathrm{kcal} / \mathrm{mol}$ ) with an energy barrier of $14.3 \mathrm{kcal} / \mathrm{mol}$. The calculation results show that 1,2-SiT process of radical $\mathbf{A}$ is both dynamically and thermodynamically favored over the corresponding 1,5HAT.

Based on our experimental DFT calculation results and previous reports ${ }^{28}$, a plausible mechanism involving $1,2-\mathrm{SiT}$ was proposed in Fig. 6. Oxidation of $\mathrm{Ag}(\mathrm{I})$ by $\mathrm{K}_{2} \mathrm{~S}_{2} \mathrm{O}_{8}$ might afford $\mathrm{Ag}$ (II) ${ }^{50}$, which would undergo ligand exchange with alcohol 1a and results in the generation of intermediate I. Homolysis of intermediate I could produce alkoxyl radical II and $\mathrm{Ag}(\mathrm{I})$. Carbon radical III would be generated through $1,2-\mathrm{SiT}$, which is favored over 1,5-HAT. Intermediate IV might be generated from the addition-elimination process between carbon radical III and compound 2, but we cannot rule out the possibility of its formation through trapping III with iminyl radical generated from homolysis of compound $\mathbf{2}$ (for details, see Supplementary information). $\mathrm{PhSO}_{2}$ radical might be converted to $\mathrm{PhSO}_{3} \mathrm{H}$ under the oxidation condition in the aqueous solution ${ }^{15} \cdot \mathrm{PhSO}_{3}{ }^{-}$ was detected by high-resolution mass spectrometry analysis of the reaction mixture, which supports this proposal (for details, see Supplementary information). The alcohol product 3 would be produced after desilylation under aqueous condition.

Scope of the reaction between $\alpha$-silyl alcohol 1a and sulfonyl oxime ether 2. Subsequently, we investigated the scope of the radical substitution reaction between $\alpha$-silyl alcohol $\mathbf{1}$ and sulfonyl oxime ether 2 . The reaction showed broad substrate scope, and various a-silyl alcohols could participate in the reaction, affording corresponding a-alkoxylimino alcohols in 48-70\% yields. When $1 \mathrm{~g}$ of $\mathbf{1 a}$ was employed, product $\mathbf{3 a}$ could be isolated in $60 \%$ yield. The reaction can tolerate many functional groups, such as $\mathrm{C}\left(\mathrm{sp}^{3}\right)-\mathrm{Br}, \mathrm{C}\left(\mathrm{sp}^{3}\right)-\mathrm{N}_{3}, \mathrm{C}\left(\mathrm{sp}^{2}\right)-\mathrm{F}, \mathrm{C}\left(\mathrm{sp}^{2}\right)-\mathrm{Cl}, \mathrm{C}$ $\left(\mathrm{sp}^{2}\right)-\mathrm{Br}, \mathrm{C}\left(\mathrm{sp}^{2}\right)-\mathrm{CN}, \mathrm{C}\left(\mathrm{sp}^{2}\right)-\mathrm{OCF}_{3}$, and an ester group. These functional groups can be used for further transformations. When the $\delta-\mathrm{C}-\mathrm{H}$ bond is next to an oxygen atom, the $1,5-\mathrm{HAT}$ of the alkoxyl radicals could be more favored, because the new radical can be stabilized by the oxygen through hyper-conjugation interaction ${ }^{30,31}$. However, under our reaction conditions, not only the normal $\delta-\mathrm{C}-\mathrm{H}$ bond can be tolerated, but the $\delta-\mathrm{C}-\mathrm{H}$ bond next to an oxygen atom can also be tolerated (Fig. 7, 3g, 3i3o, 3s). Moreover, benzylic, a-oxy, and a-benzoyloxy $\mathrm{C}-\mathrm{H}$ groups, which are usually reactive in oxidative $\mathrm{C}-\mathrm{H}$ bond cleavage reactions, are maintained under our reaction conditions (Fig. $7, \mathbf{3 g}-\mathbf{3 x})^{30,31}$. In addition, our reaction can be applied in the synthesis of alcohols, which contain a $\beta$-substituent. Compound $3 y$ was synthesized in $65 \%$ yield, which is in sharp contrast to the failure to synthesize alcohols in previous Ag-catalyzed reaction ${ }^{28}$. The relative lower yield was found for the assembly of tertiary alcohol $\mathbf{3 z}$ ( $20 \%$ yield), 3aa (31\% yield), and $\mathbf{3 a b}$ ( $41 \%$ yield). In all cases, the alcohols 3 were obtained directly after the reaction, without the extra deprotection step of anticipated silyl ether intermediate IV. In all cases, the alcohol substrates were used as limiting reagents, which further highlight the synthetic potential of the current method since the oxidative $a-\mathrm{C}-\mathrm{H}$ functionalization of alcohols usually need excess amount of alcohols, and in 


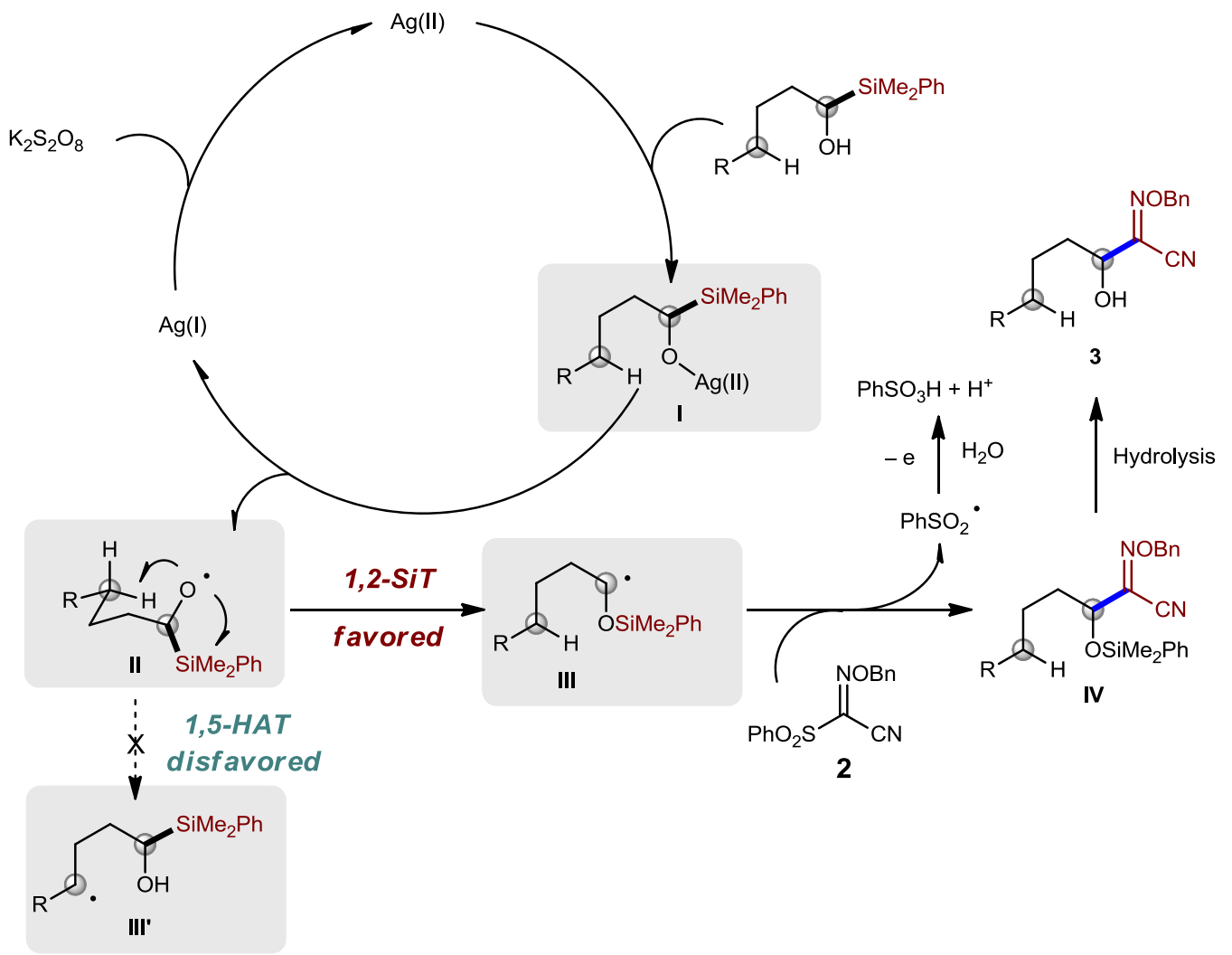

Fig. 6 Proposed mechanism. The proposed mechanism involves an $\mathrm{Ag}(\mathrm{I}) / \mathrm{Ag}(\mathrm{II})$ catalytic cycle and 1,2-SiT.

many cases, alcohols must be used as a solvent to achieve synthetic useful yield ${ }^{30,31}$.

Synthetic transformations of compound 3a. Compound 3a was easily transformed to methylated product $\mathbf{1 a - 2}$ in $57 \%$ yield, while the imine group was untouched (Fig. 8). The $\mathrm{CN}$ group could be hydrolyzed in the presence of $\mathrm{H}_{2} \mathrm{O}_{2}$ and $\mathrm{K}_{2} \mathrm{CO}_{3}$, affording amide 3a-8 in $72 \%$ yield (Fig. 8).

Radical 1,2-SiT in the catalytic Minisci reaction for the synthesis of $\boldsymbol{\alpha}$-heteroaryl alcohols. Heteroaryl groups are important structural motifs and Minisci reaction is one of the most atom-economic ways to introduce heteroaryl groups into organic molecules, by cleaving the $\mathrm{C}\left(\mathrm{sp}^{2}\right)-\mathrm{H}$ bond ${ }^{51,52}$. The $1,5-$ HAT process of alkoxyl radicals was used by Zhu's group and Chen's group in the hypervalent iodine-mediated radical Minisci reaction and various $\delta$-heteroaryl-substituted alcohols have been made $^{27,29}$. To the best of our knowledge, there has been no report on Minisci type a-heteroarylation through 1,2-HAT of alkoxyl radicals. Although direct radical $\alpha$-heteroarylation of alcohols was achieved by the intermolecular $\mathrm{H}$ abstraction, they usually need excess amount of alcohols as reagents ${ }^{31,51,52}$. In most cases, alcohols are used as the solvent, which limits the application of those methods, especially when complex alcohols are needed and/ or the alcohols are solids. Encouraged by the success of the application of radical 1,2-SiT in the direct synthesis of alkoxylimino alcohols, we probed the applicability of this strategy in the catalytic Minisci reaction for the synthesis of secondary alkyl heteroaryl alcohols.

After a quick optimization of reaction conditions (for details, see Supplementary information), we found that similar Ag-catalysis conditions could be applied in the reactions between $\alpha$-silyl alcohol 1 and heteroarenes 4 (Fig. 9). Quinolines with methyl and aryl substituents are competent reaction partners, delivering the desired a-heteroarylation products $\mathbf{5 a}-\mathbf{k}$ in $53-79 \%$ yields. The $\mathrm{F}, \mathrm{Cl}, \mathrm{Br}$, $\mathrm{CN}, \mathrm{OMe}$, and $\mathrm{Me}$ groups on the aryl substituents are tolerated. Isoquinoline derivatives such as $\mathrm{Cl}-$, , Br-, $\mathrm{MeO}-$, and $\mathrm{BnO}$-substituted isoquinolines performed well, affording products $\mathbf{5 m}-\mathbf{r}$ in $53-74 \%$ yields. An a-silyl alcohol containing a long alkyl chain also works, affording compound $5 \mathbf{r}$ in $64 \%$ yield and $5 \mathbf{t}$ in $60 \%$ yield. Moreover, phenanthridine can participate in the reaction, giving corresponding alkyl heteroaryl alcohol 5 s in $51 \%$ yield. One of the disadvantages of the previous direct $a$ heteroarylation of alcohol is the need to use excess amount of alcohol, which is formidable when the complex is applied. We found that only two equivalent of $\alpha$-silyl alcohol was required in the current radical Minisci reaction, and the relatively complex alcohols $5 \mathbf{v}-\mathbf{z}$ were prepared in $50-62 \%$ yields. It is worth noting that even benzyl alcohol can be tolerated (5aa, 50\%; 5ab, 51\%). These two compounds would be challenging to synthesize via the oxidative $\mathrm{C}-\mathrm{H}$ bond functionalization methodology because the benzyl alcohol would result in trouble $e^{30,31}$. Moreover, the synthesis of alcohols, which contain a $\beta$-substituent, was successful and compound 5ac was synthesized in $62 \%$ yield, which is in sharp contrast to the failure to synthesize alcohols in previous Agcatalyzed reaction ${ }^{28}$. Again, no $\delta$-heteroarylation products were isolated in all cases shown in Fig. 9.

\section{Discussion}

In this work, we found that the introduction of a silyl group to the a-position of alcohols can effectively inhibit 1,5-HAT of the corresponding alkoxyl radicals. The substituents on the silicon are found to be important to achieve efficient 1,2-SiT. The carbon radicals derived from 1,2-SiT are applied in the radical substitution reactions of sulfonyl oxime ether and heteroarenes to prepare $a$-alkoxylimino alcohols and alkyl heteroaryl alcohols. 


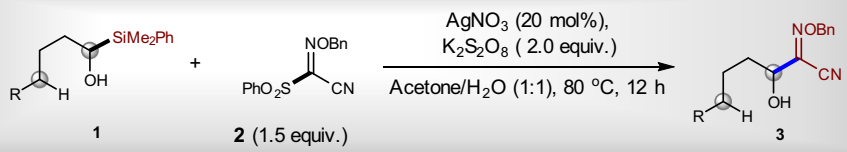

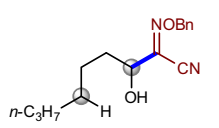

3a, $69 \%(60 \%)^{a}$

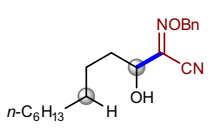

3b, $60 \%$<smiles>CC=CCCC(O)C(C#N)=NOCC</smiles>

3c, $63 \%$

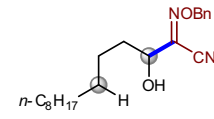

3d, $57 \%$<smiles>N#CC(=O)CCC(O)=NCCN</smiles>

3e, $47 \%$<smiles>N#CC(O)=C(O)CCCCCBr</smiles>

3f, $60 \%$

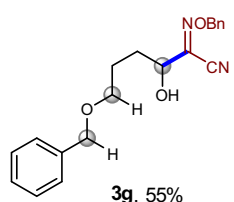<smiles>CCCCN=C(C#N)C(O)=CCC=COc1ccccc1</smiles>

3h, $60 \%$<smiles>NC(=O)C1CCC(=Cc2ccccc2F)NC1</smiles>

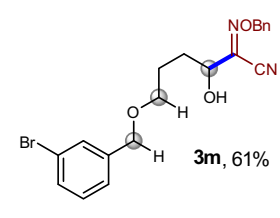

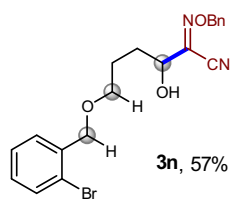<smiles>N=C(OC1CCC(C(N)=O)CC1)c1cccc(F)c1</smiles>

3j, $67 \%$<smiles>N#CC1CCC(=NC(=O)c2ccc(F)cc2)NC1</smiles>

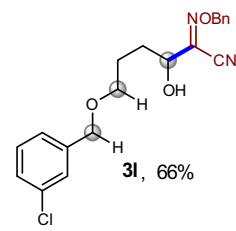

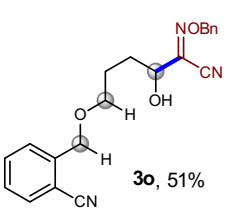

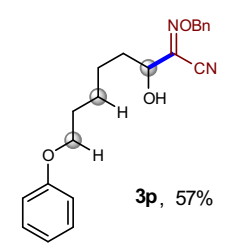<smiles>NC(=O)C1CCC(C=CC=CC(=O)c2ccccc2)CC1</smiles><smiles>N#CC(=O)C1CCC(C=CC(=O)c2ccccc2)CN1</smiles>

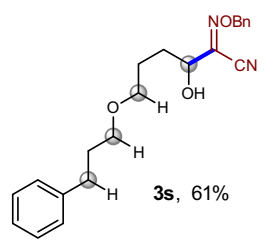<smiles>NC(=O)c1ccc(/C=C2\CCC(C(=O)O)C2)cc1</smiles>

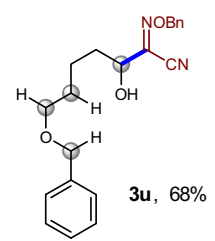

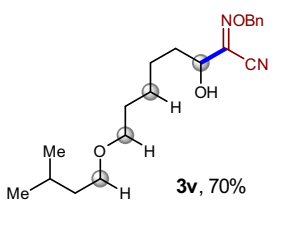

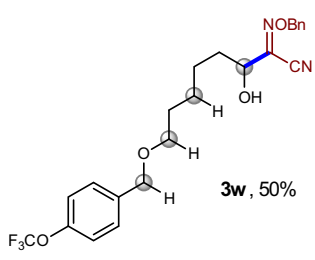

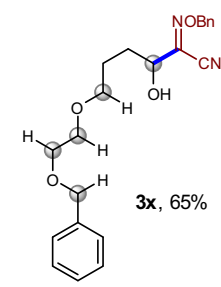<smiles>CC(CO)C(O)=C(C#N)[N+](=O)[O-]</smiles>

3y, 65\% (69:31 dr)<smiles>CCON=C(C#N)C(O)(CC)CCC(C)=O</smiles><smiles>CCCCCCCCCC(C)(C)C</smiles><smiles>CC(C)CCC(C)(O)C(C#N)=N[O+]</smiles>

$3 a b, 41 \%^{\text {b }}$

Fig. 7 Scope for the synthesis of $\boldsymbol{\alpha}$-alkoxylimino alcohols. ${ }^{a}$ The yield in the parentheses refers to the isolated yield of the gram-scale reaction. ${ }^{b}$ Acetone/ $\mathrm{H}_{2} \mathrm{O}(\mathrm{v} / \mathrm{v}=2: 1)$ was used as the solvent.

$$
\text { Mel (2.0 equiv.) }
$$

Fig. 8 The chemo-selective transformation of 3a. The oxime ether product 3a could be easily converted to methylated product $\mathbf{1 a - 2}$ and amide $\mathbf{3 a - 8}$.

Compared with the direct generation of $a$-carbon radicals from the oxidation of $\alpha-\mathrm{C}-\mathrm{H}$ bond of alcohols, the 1,2-SiT strategy distinguished itself by the generation of alkoxyl radicals, the tolerance of many functional groups such as intramolecular hydroxyl groups and $\mathrm{C}-\mathrm{H}$ bonds next to oxygen atoms, and the use of silyl alcohols as limiting reagents. Our experimental finding broadens the synthetic application of alkoxyl radicals. Further application of the 1,2-SiT of alkoxyl radicals is underway in our laboratory.

\section{Methods}

Typical procedure 1 (3a). In an Ar-protected glove box, $\mathrm{AgNO}_{3}(6.8 \mathrm{mg}, 0.04$ $\mathrm{mmol}, 20 \mathrm{~mol} \%), 2(90.0 \mathrm{mg}, 0.30 \mathrm{mmol}, 1.5$ equiv.), and $1 \mathrm{a}(50.0 \mathrm{mg}, 0.20 \mathrm{mmol})$ were added into a reaction tube. After that, the tube was taken out of the box, acetone $/ \mathrm{H}_{2} \mathrm{O}(0.75 \mathrm{~mL} / 0.75 \mathrm{~mL})$ and $\mathrm{K}_{2} \mathrm{~S}_{2} \mathrm{O}_{8}(108.0 \mathrm{mg}, 0.40 \mathrm{mmol}, 2.0$ equiv. $)$ were added under $\mathrm{N}_{2}$. The tube was then sealed, and the resulting mixture was kept stirring at $80^{\circ} \mathrm{C}$ in a heating block for $12 \mathrm{~h}$. The reaction mixture was quenched with water $(5 \mathrm{~mL})$, extracted with ethyl acetate $(3 \times 10 \mathrm{~mL})$, and the organic phase was combined and washed with brine, dried over anhydrous $\mathrm{Na}_{2} \mathrm{SO}_{4}$, and concentrated under reduced pressure. The crude product was purified with column chromatography on silica gel (200-300 mesh) with petroleum ether/ethyl acetate (PE/EA) $(8 / 1, v / v)$ as eluent to afford $38.0 \mathrm{mg}$ of the title compound as a faint yellow oil (69\% yield).

Typical procedure 2 (5a). Under $\mathrm{N}_{2}$ atmosphere, $\mathrm{AgNO}_{3}(6.8 \mathrm{mg}, 0.04 \mathrm{mmol}$, $20 \mathrm{~mol} \%), \mathrm{CH}_{3} \mathrm{CN} / \mathrm{H}_{2} \mathrm{O}(1.67 \mathrm{~mL} / 0.33 \mathrm{~mL}), 4 \mathbf{a}(28.6 \mathrm{mg}, 0.20 \mathrm{mmol}), \mathrm{CF}_{3} \mathrm{COOH}$ $\left(22.8 \mathrm{mg}, 0.2 \mathrm{mmol}, 1.0\right.$ equiv.), $1 \mathrm{a}\left(100 \mathrm{mg}, 0.40 \mathrm{mmol}, 2.0\right.$ equiv.), and $\mathrm{K}_{2} \mathrm{~S}_{2} \mathrm{O}_{8}$ (118.8 $\mathrm{mg}, 0.44 \mathrm{mmol}, 2.2$ equiv.) were added into a reaction tube. The tube was then sealed, and the resulting mixture was kept stirring at $80^{\circ} \mathrm{C}$ in a heating block for $12 \mathrm{~h}$. The reaction mixture was quenched with saturated $\mathrm{NaHCO}_{3}$ 


$$
\text { 1(2 equiv.) }
$$<smiles>CC(C)C1CCC(O)CC1c1cc(N)c2ccccc2n1</smiles>

5a, $53 \%$

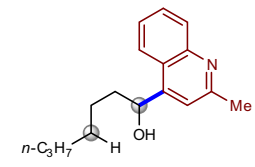

5 b, $62 \%$

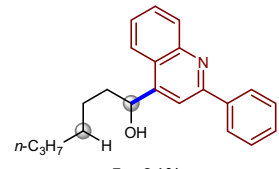

5c, $64 \%$<smiles>CCCCCC(O)=Cc1cc(-c2ccc(F)cc2)nc2ccccc12</smiles>

5d, $79 \%$

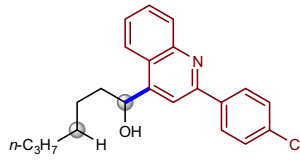

5e, $79 \%$

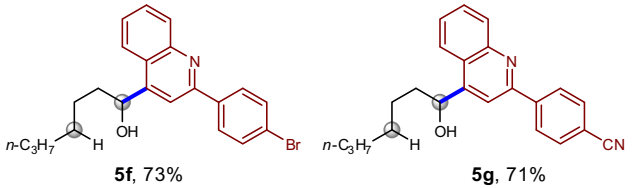

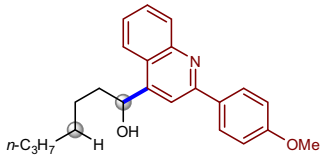

5 h, $72 \%$<smiles>CCCCCC(=O)c1cc(-c2cccc(OC)c2)nc2ccccc12</smiles>

$5 \mathbf{i}, 72 \%$

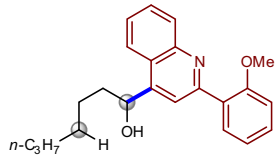

5j, $58 \%$

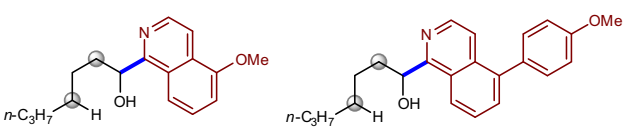

5n, $53 \%$

5o, $74 \%$

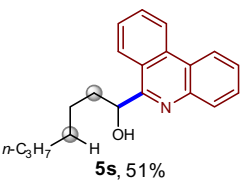

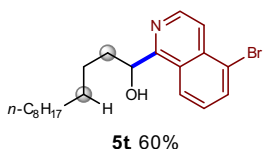

$5 \mathbf{r}, 64 \%$

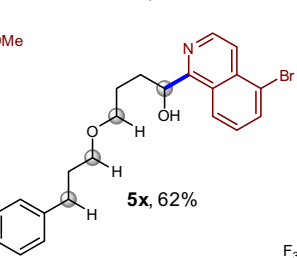<smiles>O=C(O)/C=C/CC(=O)c1nccc2c(Br)cccc12</smiles>

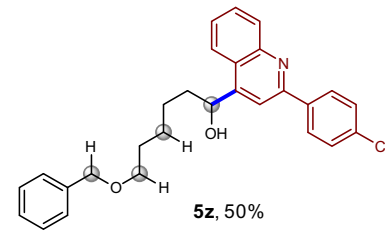

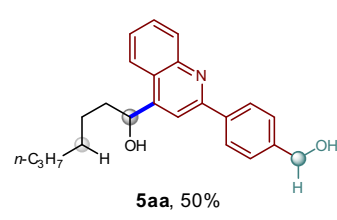<smiles>CCOC(C)c1cccc(O)c1</smiles><smiles>CCC(=O)c1cc(-c2ccc(O)cc2)nc2ccccc12</smiles>

5ab, $51 \%$<smiles>C[C@H](CO)C(=O)c1ncc(Br)c2ccccc12</smiles><smiles>CCCCCC(O)c1cnc(P)c(P)n1</smiles>

5ac, $62 \%(59: 41 \mathrm{dr}) \quad \mathbf{5 a d}, 35 \%^{\mathrm{a}}$

Fig. 9 Scope of Minisci reaction for the synthesis of $\boldsymbol{\alpha}$-heteroaryl alcohols. The reaction could tolerate various $\mathrm{C}$ - $\mathrm{H}$ bonds and benzyl alcohols that are reactive in oxidative $\mathrm{C}-\mathrm{H}$ functionalization reactions. ${ }^{\mathrm{a}} \mathrm{DMSO} / \mathrm{H}_{2} \mathrm{O}(\mathrm{v} / \mathrm{v}=5: 3)$ was used as the solvent.

aqueous solution $(10 \mathrm{~mL})$, extracted with ethyl acetate $(3 \times 10 \mathrm{~mL})$, and the organic phase was combined and washed with brine, dried over anhydrous $\mathrm{Na}_{2} \mathrm{SO}_{4}$, and concentrated under reduced pressure. The crude product was purified with column chromatography on silica gel (200-300 mesh) with PE/EA $(10 / 1, \mathrm{v} / \mathrm{v})$ as eluent to afford $27.0 \mathrm{mg}$ of the title compound as a faint yellow oil ( $53 \%$ yield)

\section{Data availability}

The authors declare that all other data supporting the findings of this study are available within the article and Supplementary information files, and also are available from the corresponding author on reasonable request.

Received: 26 October 2020; Accepted: 4 March 2021;

Published online: 09 April 2021

\section{References}

1. Smith, M. B. March's Advanced Organic Chemistry: Reactions, Mechanisms, and Structure 7th edn (Wiley, 2013).
2. Fu, G. C. Transition-metal catalysis of nucleophilic substitution reactions: a radical alternative to $\mathrm{S}_{\mathrm{N}} 1$ and $\mathrm{S}_{\mathrm{N}} 2$ processes. ACS Cent. Sci. 3, 692-700 (2017)

3. Lo, J. C. et al. Fe-catalyzed C-C bond construction from olefins via radicals. J. Am. Chem. Soc. 139, 2484-2503 (2017).

4. Yi, H. et al. Recent advances in radical C-H activation/radical cross-coupling. Chem. Rev. 117, 9016-9085 (2017).

5. Renaud, P. \& Sibi, M. P. (eds). Radicals in Organic Synthesis (Wiley-VCH, 2001).

6. Čeković, $\check{Z}$. Reactions of $\delta$-carbon radicals generated by 1,5 -hydrogen transfer to alkoxyl radicals. Tetrahedron 59, 8073-8090 (2003).

7. Jia, K. \& Chen, Y. Visible-light-induced alkoxyl radical generation for inert chemical bond cleavage/functionalization. Chem. Commun. 54, 6105-6112 (2018).

8. Guo, J.-J., Hu, A. \& Zuo, Z. Photocatalytic alkoxy radical-mediated transformations. Tetrahedron Lett. 59, 2103-2111 (2018).

9. Stateman, L. M., Nakafuku, K. M. \& Nagib, D. A. Remote C-H functionalization via selective hydrogen atom transfer. Synthesis $\mathbf{5 0}$, 1569-1586 (2018).

10. Barton, D. H. R., Beaton, J. M., Geller, L. E. \& Pechet, M. M. A new photochemical reaction. J. Am. Chem. Soc. 82, 2640-2641 (1960).

11. Čekovió, Ž., Dimttruević, L., Djokić, G. \& Srnić, T. Remote functionalisation by ferrous ion-cupric ion induced decomposition of alkyl hydroperoxides. Tetrahedron 35, 2021-2026 (1979). 
12. Kundu, R. \& Ball, Z. T. Copper-catalyzed remote $\mathrm{sp}^{3} \mathrm{C}-\mathrm{H}$ chlorination of alkyl hydroperoxides. Org. Lett. 12, 2460-2463 (2010).

13. Petrović, G. \& Čeković, Ž. Alkylation of remote non-activated $\delta$-carbon atoms: addition of $\delta$-carbon radicals, generated by 1,5 -hydrogen transfer in alkoxy radical intermediates, to activated olefins. Tetrahedron 55, 1377-1390 (1999).

14. Heusler, K. \& Kalvoda, J. Intramolecular free-radical reactions. Angew. Chem. Int. Ed. 3, 525-538 (1964).

15. Walling, C. R. \& Positive, A. Padwa Halogen compounds. VII. Intramolecular chlorinations with long chain hypochlorites. J. Am. Chem. Soc. 85, 1597-1601 (1963).

16. Concepción, J. I., Francisco, C. G., Hernández, R., Salazar, J. A. \& Suárez, E. Intramolecular hydrogen abstraction. iodosobenzene diacetate, an efficient and convenient reagent for alkoxy radical generation. Tetrahedron Lett. 25, 1953-1956 (1984).

17. Beckwith, A. L. J. \& Hay, B. P. Generation of alkoxy radicals from TValkoxypyridinethiones. J. Am. Chem. Soc. 110, 4415-4416 (1988).

18. Kim, S., Lee, T. A. \& Song, Y. Facile generation of alkoxy radicals from Nalkoxyphthalimides. Synlett 1998, 471-472 (1998).

19. Zhang, J., Li, Y., Zhang, F., Hu, C. \& Chen, Y. Generation of alkoxyl radicals by photoredox catalysis enables selective $\mathrm{C}\left(\mathrm{sp}^{3}\right)-\mathrm{H}$ functionalization under mild reaction conditions. Angew. Chem. Int. Ed. 55, 1872-1875 (2016)

20. Wang, C., Harms, K. \& Meggers, E. Catalytic asymmetric Csp ${ }^{3}-\mathrm{H}$ functionalization under photoredox conditions by radical translocation and stereocontrolled alkene addition. Angew. Chem. Int. Ed. 55, 13495-13498 (2016).

21. Zhang, J. et al. Visible-light-induced alkoxyl radicals enable alpha-C( $\left.\mathrm{sp}^{3}\right)-\mathrm{H}$ bond allylation. iScience 23, 100755 (2020).

22. Yayla, H. G., Wang, H., Tarantino, K. T., Orbe, H. S. \& Knowles, R. R. Catalytic ring-opening of cyclic alcohols enabled by PCET activation of strong O-H bonds. J. Am. Chem. Soc. 138, 10794-10797 (2016).

23. Zhao, K. et al. Catalytic ring expansions of cyclic alcohols enabled by protoncoupled electron transfer. J. Am. Chem. Soc. 141, 8752-8757 (2019).

24. Jia, K., Zhang, F., Huang, H. \& Chen, Y. Visible-light-induced alkoxyl radical generation enables selective $\mathrm{C}\left(\mathrm{sp}^{3}\right)-\mathrm{C}\left(\mathrm{sp}^{3}\right)$ bond cleavage and functionalizations. J. Am. Chem. Soc. 138, 1514-1517 (2016).

25. Hu, A., Guo, J. J., Pan, H. \& Zuo, Z. Selective functionalization of methane, ethane, and higher alkanes by cerium photocatalysis. Science 361, 668-672 (2018).

26. $\mathrm{Wu}, \mathrm{X}$. et al. Tertiary-alcohol-directed functionalization of remote $\mathrm{C}\left(\mathrm{sp}^{3}\right)-\mathrm{H}$ bonds by sequential hydrogen atom and heteroaryl migrations. Angew. Chem. Int. Ed. 57, 1640-1644 (2018).

27. $\mathrm{Wu}, \mathrm{X}$. et al. Metal-free alcohol-directed regioselective heteroarylation of remote unactivated $\mathrm{C}\left(\mathrm{sp}^{3}\right)-\mathrm{H}$ bonds. Nat. Commun. 9, 3343 (2018).

28. Zhu, Y. et al. Silver-catalyzed remote $\mathrm{Csp}^{3}-\mathrm{H}$ functionalization of aliphatic alcohols. Nat. Commun. 9, 2625 (2018).

29. Li, G. X., Hu, X., He, G. \& Chen, G. Photoredox-mediated remote C( $\left.\mathrm{sp}^{3}\right)-\mathrm{H}$ heteroarylation of free alcohols. Chem. Sci. 10, 688-693 (2019).

30. Guo, S.-r, Kumar, P. S. \& Yang, M. Recent advances of oxidative radical crosscoupling reactions: direct $\mathrm{a}-\mathrm{C}\left(\mathrm{sp}^{3}\right)-\mathrm{H}$ bond functionalization of ethers and alcohols. Adv. Syn. Catal. 359, 2-25 (2017).

31. Niu, L., Liu, J., Liang, X. A., Wang, S. \& Lei, A. Visible light-induced direct alpha C-H functionalization of alcohols. Nat. Commun. 10, 467 (2019)

32. Brook, A. G. Isomerism of some a-hydroxysilanes to silyl ethers. J. Am. Chem. Soc. 80, 1886-1889 (1958).

33. Moser, W. H. The Brook rearrangement in tandem bond formation strategies. Tetrahedron 57, 2065-2084 (2001).

34. Smith, A. B. III \& Wuest, W. M. Evolution of multi-component anion relay chemistry (ARC): construction of architecturally complex natural and unnatural products. Chem. Commun. 2008, 5883-5895 (2008).

35. Dalton, J. C. \& Bourque, R. A. Mechanistic photochemistry of acylsilanes. 2. Reaction with electron-poor olefins. J. Am. Chem. Soc. 103, 699-700 (1981).

36. Huang, C. H., Chang, S. Y., Wang, N. S. \& Tsai, Y. M. The application of intramolecular radical cyclizations of acylsilanes in the regiospecific formation of cyclic silyl enol ethers. J. Org. Chem. 66, 8983-8991 (2001).

37. Deng, Y., Liu, Q. \& Smith, A. B. III Oxidative [1,2]-Brook rearrangements exploiting single-electron transfer: photoredox-catalyzed alkylations and arylations. J. Am. Chem. Soc. 139, 9487-9490 (2017).

38. Chen, X. et al. Direct transfer of tri- and di-fluoroethanol units enabled by radical activation of organosilicon reagents. Nat. Commun. 11, 2756 (2020)

39. Kobayashi, S. \& Ishitani, H. Catalytic enantioselective addition to imines. Chem. Rev. 99, 1069-1094 (1999).

40. Gaspar, B. \& Carreira, E. M. Cobalt catalyzed functionalization of unactivated alkenes: regioselective reductive $\mathrm{C}-\mathrm{C}$ bond forming reactions. J. Am. Chem. Soc. 131, 13214-13215 (2009).

41. Mo, K. et al. Chemo- and stereoselective reduction of $\beta$-keto- $\alpha$-oximino nitriles by using Baker's yeast. Eur. J. Org. Chem. 2015, 1137-1143 (2015).

42. Gutenberger, G., Steckhan, E. \& Blechert, S. a-Silyl ethers as hydroxymethyl anion equivalents in photoinduced radical electron transfer additions. Angew. Chem. Int. Ed. 37, 660-662 (1998).
43. Jackl, M. K., Legnani, L., Morandi, B. \& Bode, J. W. Continuous flow synthesis of morpholines and oxazepanes with silicon amine protocol (slap) reagents and lewis acid facilitated photoredox catalysis. Org. Lett. 19, 4696-4699 (2017).

44. Khatun, N., Kim, M. J. \& Woo, S. K. Visible-light photoredox-catalyzed hydroalkoxymethylation of activated alkenes using a-silyl ethers as alkoxymethyl radical equivalents. Org. Lett. 20, 6239-6243 (2018).

45. Nam, S. B., Khatun, N., Kang, Y. W., Park, B. Y. \& Woo, S. K. Controllable onepot synthesis for scaffold diversity via visiblelight photoredox-catalyzed giese reaction and further transformation. Chem. Commun. 56, 2873-2876 (2020).

46. Yoshida, J., Maekawa, T., Murata, T., Matsunaga, S. \& Isoe, S. The origin of $\beta$ silicon effect in electron-transfer reactions of silicon-substituted heteroatom compounds. electrochemical and theoretical studies. J. Am. Chem. Soc. 112, 1962-1970 (1990)

47. Short, M. A., Shehata, M. F., Sanders, M. A. \& Roizen, J. L. Sulfamides direct radical-mediated chlorination of aliphatic C-H bonds. Chem. Sci. 11, 217 (2020).

48. Houk, K. N. et al. Distortion-controlled reactivity and molecular dynamics of dehydro-Diels-Alder reactions. J. Am. Chem. Soc. 138, 8247-8252 (2016).

49. Xu, X. F. \& Truhlar, D. G. Accuracy of effective core potentials and basis sets for density functional calculations, including relativistic effects, as illustrated by calculations on arsenic compounds. J. Chem. Theory Comput. 7, 2766-2779 (2011).

50. Walling, C. \& Camaioni, D. M. Role of silver(II) in silver-catalyzed oxidations by peroxydisulfate. J. Org. Chem. 43, 3266-3271 (1978).

51. Duncton, M. A. J. Minisci reactions: versatile $\mathrm{CH}$-functionalizations for medicinal chemists. MedChemComm 2, 1135 (2011)

52. Proctor, R. S. J. \& Phipps, R. J. Recent advances in Minisci-type reactions Angew. Chem. Int. Ed. 58, 13666-13699 (2019).

\section{Acknowledgements}

We are grateful to NSFC $(21901191,21822303)$, Fundamental Research Funds for the Central Universities (2042018kf0023, 2042019kf0006), State Key Laboratory of Bioorganic \& Natural Products Chemistry (BNPC18237), and Wuhan University for financial support. We are thankful to Prof. Aiwen Lei and Prof. Xumu Zhang at Wuhan University for the generous provision of the basic instruments.

\section{Author contributions}

X.S. designed and directed the investigations and composed the manuscript with revisions provided by the other authors. Z.Y. and Y.N. developed the catalytic method. Z.Y. Y.N., and S.C. studied the substrate scope. X.H. and Y.L. conducted the calculations. Z.Y., Y.N., X.H., S.C., S.L., Z.L., X.C., Y.Z., Y.L., and X.S. were involved in the analysis of results and discussions of the project.

\section{Competing interests}

The authors declare no competing interests.

\section{Additional information}

Supplementary information The online version contains supplementary material available at https://doi.org/10.1038/s41467-021-22382-y.

Correspondence and requests for materials should be addressed to Y.L. or X.S.

Peer review information Nature Communications thanks the anonymous reviewers for their contribution to the peer review of this work. Peer reviewer reports are available.

Reprints and permission information is available at http://www.nature.com/reprints

Publisher's note Springer Nature remains neutral with regard to jurisdictional claims in published maps and institutional affiliations.

Open Access This article is licensed under a Creative Commons Attribution 4.0 International License, which permits use, sharing, adaptation, distribution and reproduction in any medium or format, as long as you give appropriate credit to the original author(s) and the source, provide a link to the Creative Commons license, and indicate if changes were made. The images or other third party material in this article are included in the article's Creative Commons license, unless indicated otherwise in a credit line to the material. If material is not included in the article's Creative Commons license and your intended use is not permitted by statutory regulation or exceeds the permitted use, you will need to obtain permission directly from the copyright holder. To view a copy of this license, visit http://creativecommons.org/ licenses/by/4.0/

(c) The Author(s) 2021 